\title{
Introducing teleconferencing to Turkey: Partnerships that work!
}

\author{
Karen L. Murphy \\ University of Washington
}

\begin{abstract}
This paper describes the planning and results of Turkey's first international multi-point audio teleconference. The technology existed, and teleconferencing equipment and expertise were both available. Yet a multipoint teleconference had never been done before. The teleconference was the result of a carefully planned partnership between the Turkish government, private industry, and a major university. The paper concludes with a discussion of the potential of instructional teleconferencing in Turkey.
\end{abstract}

Turkey's first multi-point audio teleconference was held in April, 1988. Four locations were connected by the PTT conference bridge in Ankara, the capital. The teleconference was held during the Annual Conference of the Association of European Correspondence Schools (AECS) that took place in Istanbul at the Etap Marmara Hotel from 11-15 April. The theme of the Conference was Innovations in Distance Education (Murphy, 1988).

AT\&T in Cincinnati, Ohio, originated the telephone call, and the Turkish PTT (Post, Telephone, \& Telegraph) linked the conference room in Istanbul, Anadolu University's Open Education Faculty in Eskisehir, and the Ministry of Education in Ankara. (Credit for Figure 1, a diagram of this teleconference, goes to Refik Arkut of Northern Telecom.)

I coordinated that audio teleconference and had invited Dr. Alan Chute, Manager of the National Teletraining Network of AT\&T, to be the guest lecturer. Alan's slide-lecture demonstrated ways that AT\&T uses teleconferencing to train its employees and clients. At the end of the slide lecture, people at each location were able to ask questions of both Alan and me. 


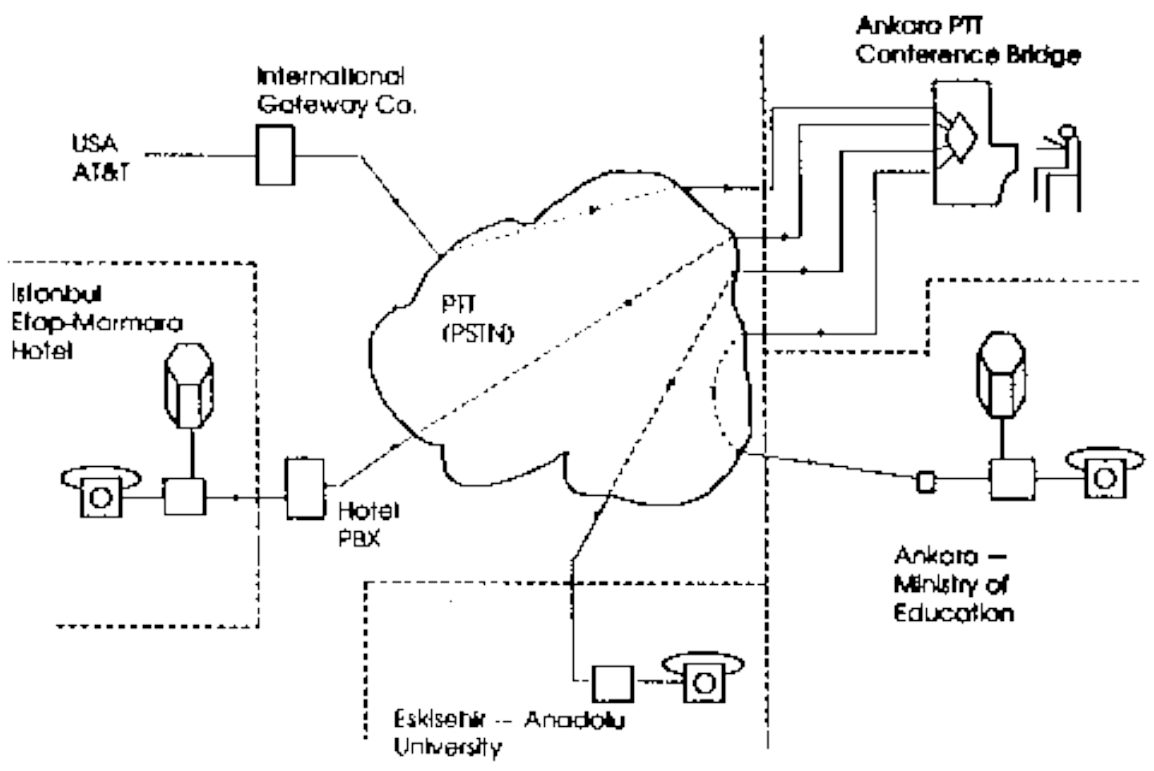

Figure 1: Diagram of Turkey's first multi-point audio teleconference in April, 1988

Coordinators at each location - Ankara, Eskisehir, and Istanbul - had been trained to assist the teleconference, and AT\&T sent slides and printed materials in advance to each of the coordinators. These slides accompanied Alan's talk at each location, and every participant was provided a copy of the abstract of the AT\&T presentation.

\section{Barriers to Implementation}

Was this a simple audio conference? On the surface, the undertaking looks straightforward. However, barriers arose at every step of the eight-month preparation. To those of you who are experienced in arranging teleconferences, and to those of you who have experience working in developing countries, such problems would be expected. Some of the problems that were encountered are specific to Turkey, and others were more general. First, multipoint audio teleconferencing had never been done before in Turkey. Second, Turkish people, like others in the developing world who desire the high technology of the West, had expectations for a Hollywood kind of video teleconference. Third, Turkish people depend primarily on face-to-face contacts and feel uncomfortable when they cannot utilise nonverbal cues. Fourth, I am a non-technical 
female who attempted to introduce an innovation in a male-dominated society. Finally, I was the only person who had an initial stake in implementing a teleconference.

\section{Bases of Power}

The success of Turkey's first multi-point audio teleconference was related to four elements of power. The four power bases which were relevant to introducing this innovation are: expert power, reward power, referent power, and connection power (Hersey and Blanchard, 1982). The examples that I will describe are specific to this particular case, although the power bases from which a leader operates are relevant in any situation.

\section{Expert Power}

The first source of power is expert power. Expert power is based on the leader's possession of expertise, skill, and knowledge, which, through respect, influence others.

1. Experience in teletraining at ATET: My three-month internship in the National Teletraining Center at AT\&T in Cincinnati provided me with the expertise, skill, and knowledge of teleconferencing necessary to prepare for and conduct an audio conference in Turkey. I subsequently conducted an audiographic teleconference with Optel's Voice Too equipment while teaching at the University of Washington.

2. Teaching/training and managerial skills, both in the US and in Turkey: Over 20 years of teaching and training in the US and in Turkey, and five years of managing a cultural exchange program between the US and Turkey provided me with the expertise needed to train coordinators and manage the logistics of developing the teleconference.

\section{Reward Power}

The second source of power is reward power. Reward power is based on the leader's ability to provide rewards for other people who believe that compliance will lead to positive incentives such as pay, promotion, or recognition.

1. Northern Telecom's increased business opportunities: Northern Telecom expected to generate increased business with PTT as a result of this audio teleconference. They provided their Conference 200 equipment for two of the locations for the teleconference.

2. The Ministry of Education's increased recognition: The branch of the Ministry of Education responsible for the teleconference in Ankara, the Research and Development Center, hoped to gain recognition at higher levels of the Ministry and at Anadolu University. 
3. FONO Correspondence School's increased recognition: FONO

Correspondence School, which acted as the local coordinator of the AECS conference, also hoped to gain recognition of the Ministry of Education and of Anadolu University, which is the other widespread distance education system in Turkey.

4. Anadolu University's increased recognition: Anadolu University hoped to gain recognition throughout Turkey and internationally as an effective distance education system.

\section{Referent Power}

The third source of power is referent power. Referent power is based on the leader's personal traits and characteristics.

1. Persistence: Even when I was unable to locate a PTT official who would enable the teleconference, and repeated attempts failed to link the three sites in Turkey, persistence resulted in success.

2. Air of competence and professionalism: By demonstrating an air of competence and professionalism, even though nominally I was a graduate student doing research at Anadolu University, I generated respect and compliance.

3. Organisational skills: In a culture where time does not have the same value as in the US, it was important to be organised while maintaining a flexible timetable. More difficult was imposing my timetable on others who did not perceive the need to observe schedules similarly.

4. Cultural adaptability: understanding, and knowledge of the language: Having lived for five years in Turkey, and having learned Turkish at a conversational level of fluency, I was prepared culturally to deal with the daily idiosyncrasies.

5. Respect for authority and air of humility: Not assuming that I had all the knowledge and ability myself, I demonstrated respect for authority and instilled a sense of cooperation among those who were involved in the teleconference.

\section{Connection Power}

The fourth source of power is connection power. Connection power is based on the leader's "connections" with influential or important persons inside or outside the organisation.

1. Anadolu University: As I was currently a Fulbright Researcher at the Open Education Faculty at Anadolu University, I asked the Dean of the Faculty to telephone an official at PTT to arrange a meeting; the university assumed the costs for the local transmission time for both the teleconference and the dry run which preceded it. 
2. ATET: As I had recently completed an internship in the National Teletraining Center at AT\&T in Cincinnati, the manager, Alan Chute, agreed to be the guest lecturer for the teleconference and to have AT\&T assume the international costs.

3. AECS: The AECS conference coordinator, Torstein Rekkedal of Norway, sent me the announcement of the conference because of our research connections through another organisation, ICDE (the International Council for Distance Education).

4. Northern Telecom: I met the country director of Northern Telecom while standing in line at Heathrow Airport to board the airplane to take us to Turkey; Northern Telecom later provided the teleconferencing equipment for all three sites in Turkey.

5. PTT: Because of my connections at Northern Telecom, I learned from a PTT official that such a multi-point audio teleconference was technically possible.

6. Ministry of Education: The director of FONO Correspondence School, the local conference coordinator, provided me with introductions at the Ministry of Education, who then hosted the teleconference in Ankara.

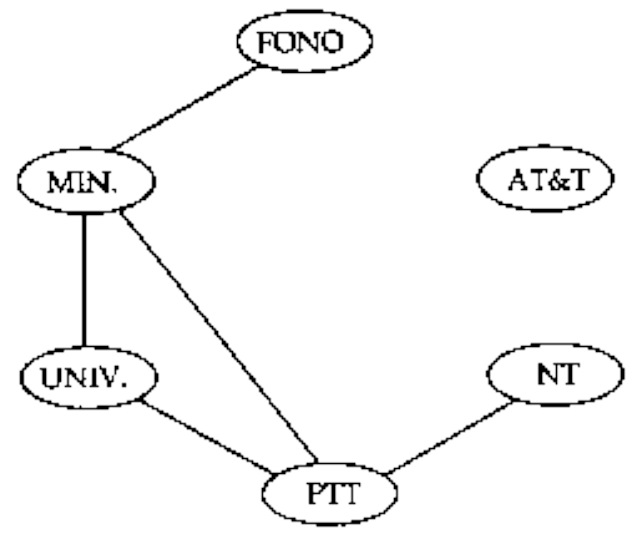

Figure 2: Connections that existed prior to the teleconference

The individual participants in the teleconference were AT\&T in the US, and in Turkey included Northern Telecom, PTT, Anadolu University, the Ministry of Education, and FONO Correspondence School in conjunction with the AECS conference. The connections that existed prior to the plans for the teleconference were extremely limited (see Figure 2). However, in a country like Turkey where connections even at the higher levels are frequently based on personal relationships, it was necessary to establish strong links among all the participants. 


\section{Teleconferencing in Turkey}

Two-way point-to-point video conferencing in Turkey was first demonstrated in October, 1986, during the exhibition of the 145th anniversary of PTT. The first commercial application of teleconferencing was during Summer, 1987, when Prime Minister Turgut Ozal gave a press conference by satellite video from Houston, Texas. As of the end of Summer, 1988, a total of eleven two-way video conferences had been conducted in Turkey; ten of these allowed the Prime Minister, from the capital in Ankara, to open a meeting or a conference held in Istanbul, and only one was a meeting held by teleconference not involving the Prime Minister, between Istanbul and Ankara (personal communication, PTT officials, September, 1988).

The history of multi-point audio conferencing in Turkey is brief, as was earlier described. Turkeys first and only multi-point audio conference to date was conducted in April, 1988, though several companies report that they have conducted two-way business meetings utilising audio conference telephones (personal communication, Central Bank officials, July, 1988; Profilo Company officials, September, 1988). The PTT presently can connect as many as six locations with a conference bridge. They report that Conference Call, which is one of the subscriber features in digital exchanges, will be available in the near future (personal communication, PTT officials, April, 1988). This means that people who want to participate in an audio teleconference will be able to dial a telephone number from their own telephone set and be connected with several other sites.

Today, the Turkish PTT is interested in promoting two-way video teleconferencing. There are three mobile units available for rent, and the current technology supports two-way video conferencing only. In the future, any teleconferencing hardware and software purchases must be approved by the PTT.

\section{Potential of Teleconferencing}

Teleconferencing in Turkey offers a number of exciting possibilities and some serious drawbacks. Instructional teleconferencing can be used for seminars and tutorials in the existing distance education programs, at the university level, in the Ministry of Education, and in corporate and organisation training.

Let us look at the example of the potential for teleconferencing at the primary distance education program - the Open Education Faculty of Anadolu University. The Open Education Faculty, with its central administrative bureau in Eskisehir, serves over 150,000 university students throughout the country. Instruction in business administration and 
economics is delivered primarily through printed materials supported by broadcast television and radio programs, face-to-face lectures, and a small number of video education centers. Currently the Open Education Faculty has 20 service bureaus throughout Turkey which perform administrative functions (The Open Education Faculty of Anadolu University, 1988). (See Figure 3 for a map of Turkey and the Open Education Faculty administrative bureaus.)

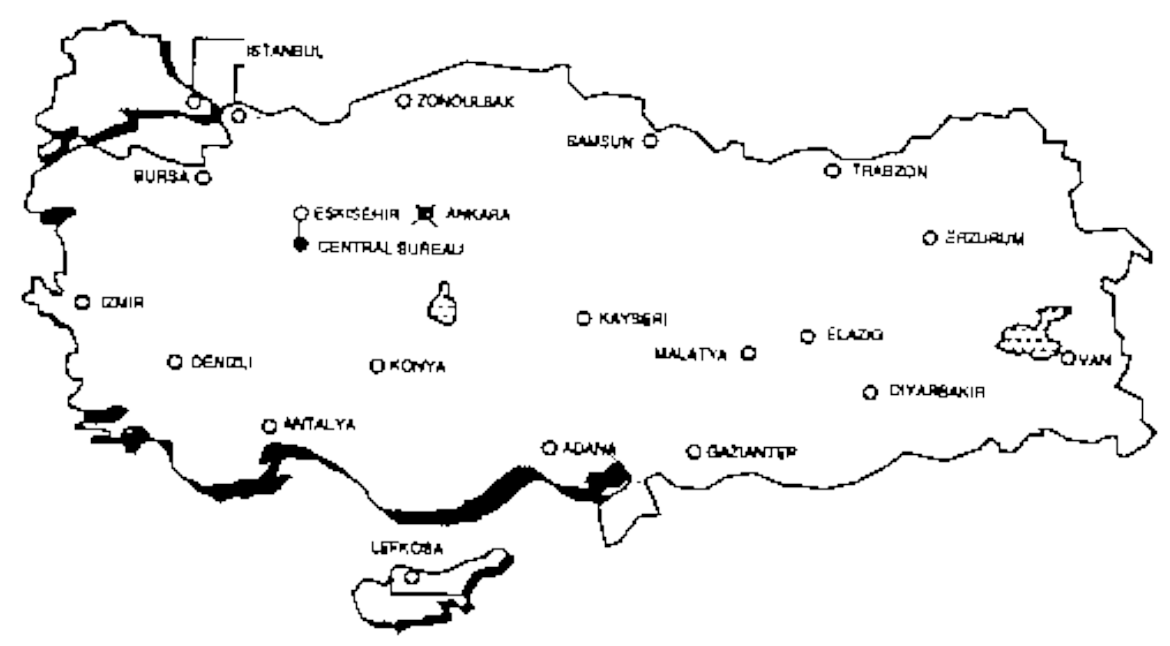

Figure 3: Turkey showing the 20 administrative bureaus of the Open Education Faculty

Audio teleconferencing, or one-way video and two-way audio conferencing, conducted at the bureaus, would save precious time and expense of travel to Eskisehir and would provide interaction with a variety of people who are not currently served. The following suggestions can be made to use teleconferencing at Anadolu University:

1. Meetings: Teleconferencing can be used for business meetings, such as meetings with the directors of the bureaus.

2. Training: Teleconferencing ("teletraining") can be used to train bureau directors, instructors, and those who work with Advising Services.

3. Sharing Instructors: Teleconferencing can be used by instructors to teach classes to students who are located elsewhere, such as Kutahya, Bursa, and Northern Cyprus.

4. Tutorials: Teleconferencing can be used to provide tutorials at specific times to students at their nearby bureaus. 
5. TV Question and Answer: Teleconferencing can be used by instructors in the television studio at the university to answer questions by telephone from students.

Current interest in Turkey in implementing pilot projects connected with instructional teleconferencing exists at Anadolu University's Open Education Faculty, at a development foundation, at the Ministry of Education, and at the office of one of the State Ministers.

Numerous drawbacks to implementing teleconferencing in Turkey can be cited, and several of these have already been mentioned. First, teleconferencing relies on a technology in which the quality of both service and equipment are variable. In Turkey, where telecommunications lines are not fully developed and where costs are still high, it may be difficult to count on clear, steady sound transmission. In addition to technical drawbacks to implementing teleconferencing are cultural barriers. The emphasis on face-to-face communication is a strong barrier to acceptance of audio teleconferencing, which relies primarily on voice communication, supported by visual materials. Another cultural issue is that of the informal hierarchy, which frequently is more influential than the formal hierarchy. It is generally necessary to find a "torpil," or a person who is in a position to intervene for you. For that reason, connection power may take on new meaning in Turkey and other developing countries.

Although my own presence in Turkey was transitory, the connections that were established as a result of the multi-point teleconference may be considered permanent (see Figure 4). Links between and among all of the different participants were established, thus providing an infrastructure enabling future teleconferences to occur more easily.

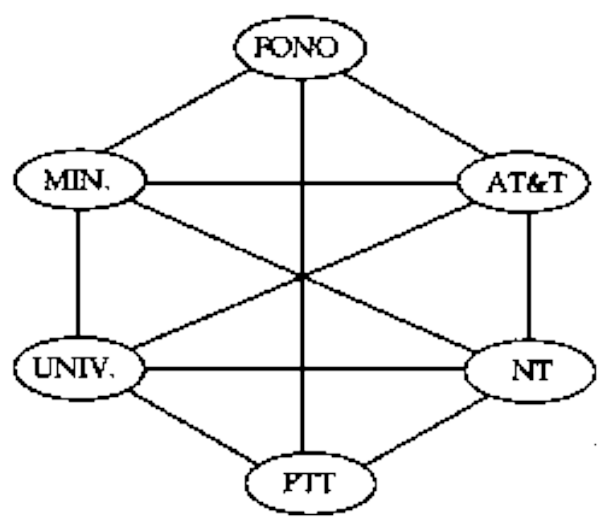

Figure 4: Connections that existed after the teleconference 


\section{References}

Hersey, P., \& Blanchard, K. (1982). Management of organisational behaviour. Englewood Cliffs, NJ: Prentice-Hall.

Murphy, K. L. (1988). The integration of teleconferencing in distance teaching. Paper presented at the Fourth Annual Conference of the Association of European Correspondence Schools, Istanbul, Turkey, April.

The Open Education Faculty of Anadolu University. (1988). Eskisehir, Turkey: Anadolu University, Open Education Faculty.

Author: Karen Murphy is a doctoral student at the University of Washington. Her paper was initially prepared for presentation to TeleCon VIII at Anaheim, California in 1988. Her address is 412 Miller Hall, DQ-12, University of Washington, Seattle, WA 98195, United States of America.

Please cite as: Murphy, K. L. (1989). Introducing teleconferencing to Turkey: Partnerships that work! Australian Journal of Educational Technology, 5(1), 14-22. http: / / www.ascilite.org.au/ajet/ajet5/murphy.html 